Article

\title{
Electroless Nickel-Based Catalyst for Diffusion Limited Hydrogen Generation through Hydrolysis of Borohydride
}

\author{
Shannon P. Anderson and Egwu E. Kalu* \\ Department of Chemical \& Biomedical Engineering, FAMU-FSU College of Engineering, \\ Tallahassee, FL 32310, USA; E-Mail: spa06c@my.fsu.edu
}

* Author to whom correspondence should be addressed; E-Mail: ekalu@eng.fsu.edu; Tel.: +1-850-410-6327; Fax: +1-850-410-6150.

Received: 31 May 2013; in revised form: 5 July 2013 / Accepted: 15 July 2013 /

Published: 19 July 2013

\begin{abstract}
Catalysts based on electroless nickel and bi-metallic nickel-molybdenum nanoparticles were synthesized for the hydrolysis of sodium borohydride for hydrogen generation. The catalysts were synthesized by polymer-stabilized Pd nanoparticle-catalyzation and activation of $\mathrm{Al}_{2} \mathrm{O}_{3}$ substrate and electroless $\mathrm{Ni}$ or Ni-Mo plating of the substrate for selected time lengths. Catalytic activity of the synthesized catalysts was tested for the hydrolyzation of alkaline-stabilized $\mathrm{NaBH}_{4}$ solution for hydrogen generation. The effects of electroless plating time lengths, temperature and $\mathrm{NaBH}_{4}$ concentration on hydrogen generation rates were analyzed and discussed. Compositional analysis and surface morphology were carried out for nano-metallized $\mathrm{Al}_{2} \mathrm{O}_{3}$ using Scanning Electron Micrographs (SEM) and Energy Dispersive X-Ray Microanalysis (EDAX). The as-plated polymer-stabilized electroless nickel catalyst plated for $10 \mathrm{~min}$ and unstirred in the hydrolysis reaction exhibited appreciable catalytic activity for hydrolysis of $\mathrm{NaBH}_{4}$. For a zero-order reaction assumption, activation energy of hydrogen generation using the catalyst was estimated at $104.6 \mathrm{~kJ} / \mathrm{mol}$. Suggestions are provided for further work needed prior to using the catalyst for portable hydrogen generation from aqueous alkaline-stabilized $\mathrm{NaBH}_{4}$ solution for fuel cells.
\end{abstract}

Keywords: hydrogen generation; borohydride; nickel; catalyst 


\section{Introduction}

Proton Exchange Membrane Fuel Cells (PEMFC) can be used to generate clean electrical energy from a hydrogen source. Issues of generation and storage of hydrogen fuel for PEMFCs are currently being tackled [1]. Chemical hydrogen storage found in such compounds as boro- and metal hydrides contains hydrogen densities ranging from 10 to 20 wt \% [2], which is preferred over physically stored hydrogen, such as in compressed gaseous or liquid $\mathrm{H}_{2}$ [1]. Accordingly, sodium borohydride $\left(\mathrm{NaBH}_{4}\right)$ and ammonia borane $\left(\mathrm{NH}_{3} \mathrm{BH}_{3}\right)$ are the two main compounds currently being studied seriously for hydrogen generation, due to their high storage densities of 10.8 and $19.6 \mathrm{wt} \%$, respectively [3-10]. As $\mathrm{NH}_{3} \mathrm{BH}_{3}$ has greater storage density than $\mathrm{NaBH}_{4}$, many workers have focused their efforts on its uses-especially for possible automobile applications. However, despite the loss of favor of the US Department of Energy for a potential source of chemical hydrogen for automobile use, $\mathrm{NaBH}_{4}$ can still be used to generate hydrogen for use in mobile and portable devices [11].

Sodium borohydride generates pure hydrogen via a hydrolysis reaction according to Equation (1):

$$
\mathrm{NaBH}_{4}+2 \mathrm{H}_{2} \mathrm{O} \rightarrow \mathrm{NaBO}_{2}+4 \mathrm{H}_{2}
$$

In order to prevent the spontaneous generation of hydrogen from $\mathrm{NaBH}_{4}$ solutions, alkaline solutions are prepared and, thus, allowed solutions to be stored safely until use [7,12]. A catalyst is needed to promote hydrogen generation from these alkaline solutions. Another advantage $\mathrm{NaBH}_{4}$ has over $\mathrm{NH}_{3} \mathrm{BH}_{3}$ is that the $\mathrm{NaBO}_{2}$ by-product can be recycled to synthesize $\mathrm{NaBH}_{4}$ [12-14]. Metal catalysts have been shown to be effective promoters for hydrogen generation from the hydrolysis of $\mathrm{NaBH}_{4}$. Although noble metal catalysts, like Pt- [15,16], Pd- [17] and Ru-based [18,19] catalysts, show higher catalytic activity, they are more expensive and, thus, would not be favorable for commercial use. Many recent works have focused on using $\mathrm{Co}$ [20] and/or $\mathrm{Ni}$, as well as the alloys $[7,8,21,22]$ of these metals to synthesize catalysts for hydrolysis applications. Although Co shows greater catalytic activity than $\mathrm{Ni}$ [21], it is also more expensive, but not as expensive as the noble metals. Using Ni-based catalysts for hydrolysis could reduce the cost of the final portable energy device.

In this paper, we study the catalytic hydrolysis of alkaline $\mathrm{NaBH}_{4}$ solution with limited diffusion using electrolessly prepared Ni-based catalysts. Electroless deposition, also called auto-catalytic plating, is a process that involves simultaneous chemical reactions that deposit metal particles onto an activated support surface. It can be used for abrasion and wear resistance, corrosion resistance, to build up thickness and many other applications. Instead of using electricity to drive the reaction, like in electrode position, physical and chemical conditions are used to drive and control the electroless deposition reaction. This is a favorable approach to prepare catalysts because: (i) it lends itself to the use of different types of substrates as supports; (ii) the electroless solution can be specially formulated and controlled to deposit a variety of metals, alloys and co-deposition of metalloids, thus allowing the design of specific catalyst configurations. The advantage of electroless deposition over the classical impregnation method includes the controlled (unlike the spontaneous nature of impregnation technique) nature of electroless deposition that can lead to selective deposition and better microstructural and thickness control $[23,24]$. 
A two-step approach was used in the present investigation. In the first step, the design of experiment (DOE) technique was used to estimate the significance of five selected factors (involving the catalyst and hydrolysis conditions) on the volume of hydrogen generated. The catalysts whose performances in the hydrolysis reaction were promising were further put through a second set of experiments to examine the effects of reaction temperature and $\mathrm{NaBH}_{4}$ concentration on the gas generation rate. Kinetic parameters were estimated from the set of data generated. As none of the hydrolysis experiments reported in this work were stirred or agitated (diffusion-limited), the parameters in this work represent the lowest performance level for the catalysts prepared. The diffusion-limited condition is thought to be a good representation of what can possibly occur inside an unstirred hydrogen generator reactor for use in a hand-held device. With an installed system to stir the contents of the hydrogen generator reactor, an additional means of powering such a system would be needed, thus increasing the potential cost of the whole device. Thus, the overall goal is to show that electroless deposition can be used to prepare an effective catalyst for the hydrolysis of $\mathrm{NaBH}_{4}$ solution to generate hydrogen for applications in simple hand-held devices that may not need a stirred hydrogen generator reactor. This paper reports on the diffusion-limited electroless Ni-Mo-P catalysis of $\mathrm{NaBH}_{4}$ hydrolysis for hydrogen generation. The chemical kinetics of electroless Ni-Mo-P-catalyzed $\mathrm{NaBH}_{4}$ hydrolysis is reported.

\section{Results and Discussion}

\subsection{Surface Characterization and Composition}

A study of the surface morphology was done using a Zeiss 1540 XB Cross Beam Scanning Electron Microscope (SEM) equipped with an Energy Dispersive X-ray (EDX). Figure 1 compares the SEM surface images of selected DOE samples. The morphology of the two samples shows that increases in plating time results in more rounded, bigger and uniformly plated particles. As to be expected, the 2 min plated samples reveal that less metal was deposited on the substrate surface.

EDAX plots and compositional charts only present a representative section of a sample, so the composition and area percents given are not completely definitive of the entire catalyst sample.

EDAX measurement at small sample areas of Ni-P and Ni-Mo-P catalyst samples plated for 2 and $10 \mathrm{~min}$ are shown in Figure 2. Figure 2a,b indicates that the electroless Ni bath used successfully plated $\mathrm{Ni}$ on the $\mathrm{Pd}$ catalyzed $\mathrm{Al}_{2} \mathrm{O}_{3}$ surface. The amount of $\mathrm{Ni}$ plated increased with increased plating time, as expected. The presence of co-deposited $\mathrm{P}$ was only indicated for the sample plated for $10 \mathrm{~min}$. Compositional tables that accompanied the EDAX plots reveal that a disproportionate amount of $\mathrm{Ni}$ was plated for the 2 and 10 min samples. Assuming a proportional deposition, the 10 min samples are expected to have at least five times more $\mathrm{Ni}$ deposited on the substrate in comparison to the $2 \mathrm{~min}$ samples. However, the results obtained show that with weight percentages of 4.63 and 12.41 for the 2 and 10 min samples, respectively, plating time and deposited metal weight are not proportional. The induction time to initiate deposition could be a factor in accounting for the non-proportionality of deposited materials with time. The electroless Ni-Mo-P bath deposited $\mathrm{Ni}$ and Mo on the Pd catalyzed $\mathrm{Al}_{2} \mathrm{O}_{3}$ surface, similar to the results obtained for the $10 \mathrm{~min} \mathrm{Ni}-\mathrm{P}$ samples. 
Figure 1. Scanning Electron Micrographs (SEM) image of Ni-P plated for (a) 2 min; (b) $10 \mathrm{~min}$.

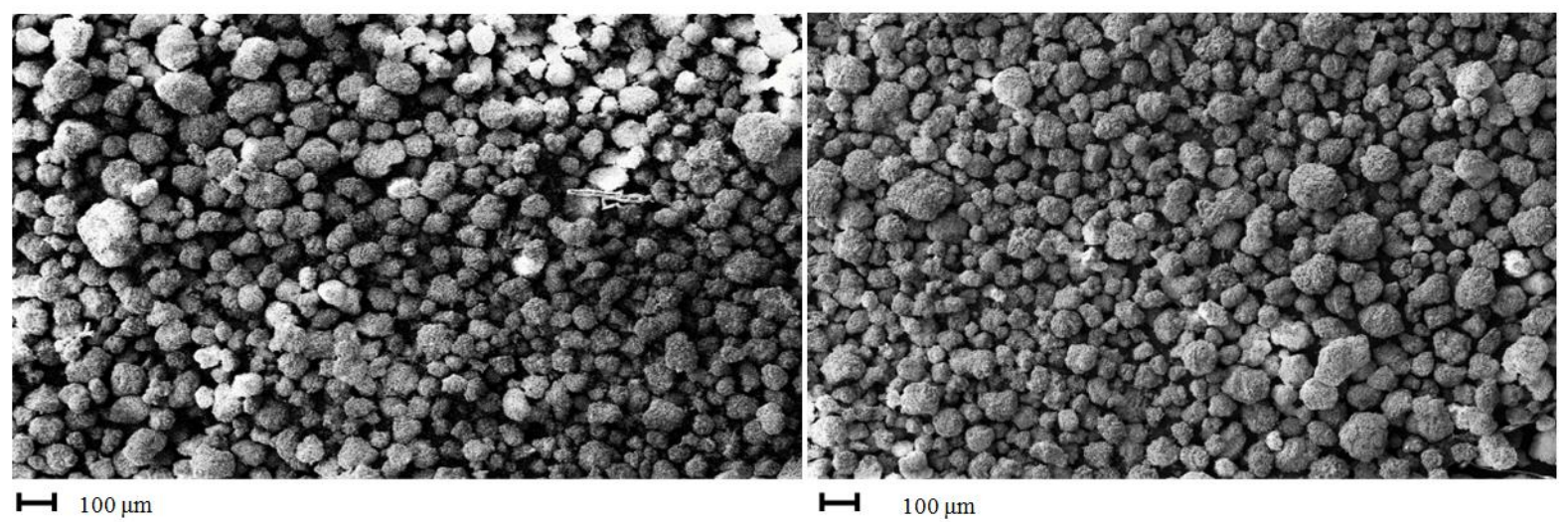

(a)

(b)

The composition of the electroless Ni-Mo-P bath was richer in Ni and Mo ions, and more Ni plated the substrate surface than Mo, as expected. The Mo was added to improve the corrosion resistive property of the material. The hypophosphite reducing agent used often breaks down, leading to co-deposition of phosphorus with the metal. The presence of co-deposited phosphorous was only indicated in Figure 2b. Although phosphorus was not identified at all the sampled points, it is imperative to understand that even if phosphorus is not identified on a particular sampled point, it does not mean that it did not plate onto the surface at other locations. EDAX measures at relatively small sample area, and phosphorous may not have co-deposited on the areas tested.

Figure 2. Energy Dispersive X-Ray Microanalysis (EDAX) plots of a section of (a) Ni-P plated for $2 \mathrm{~min}$; (b) Ni-P plated for $10 \mathrm{~min}$; (c) Ni-Mo-P plated for $2 \mathrm{~min}$; (d) Ni-Mo-P plated for $10 \mathrm{~min}$.

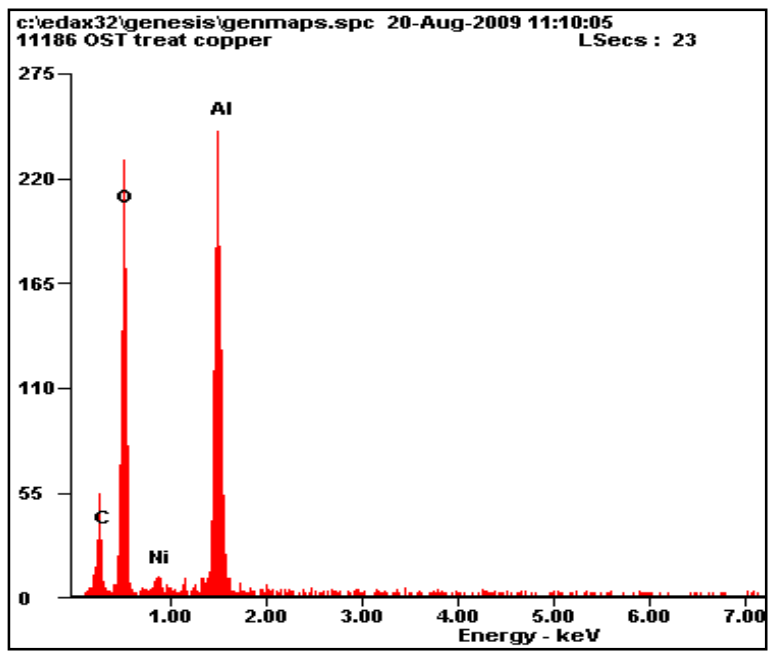

\begin{tabular}{l|l|l|}
\hline Element & $\mathbf{W t} \%$ & $\mathbf{A t} \%$ \\
\hline CK & 23.30 & 35.15 \\
\hline OK & 32.59 & 36.91 \\
\hline NiL & 04.63 & 0.143 \\
\hline AlK & 39.48 & 26.51 \\
\hline Matrix & Correction & ZAF \\
\hline
\end{tabular}

(a) 
Figure 2. cont.

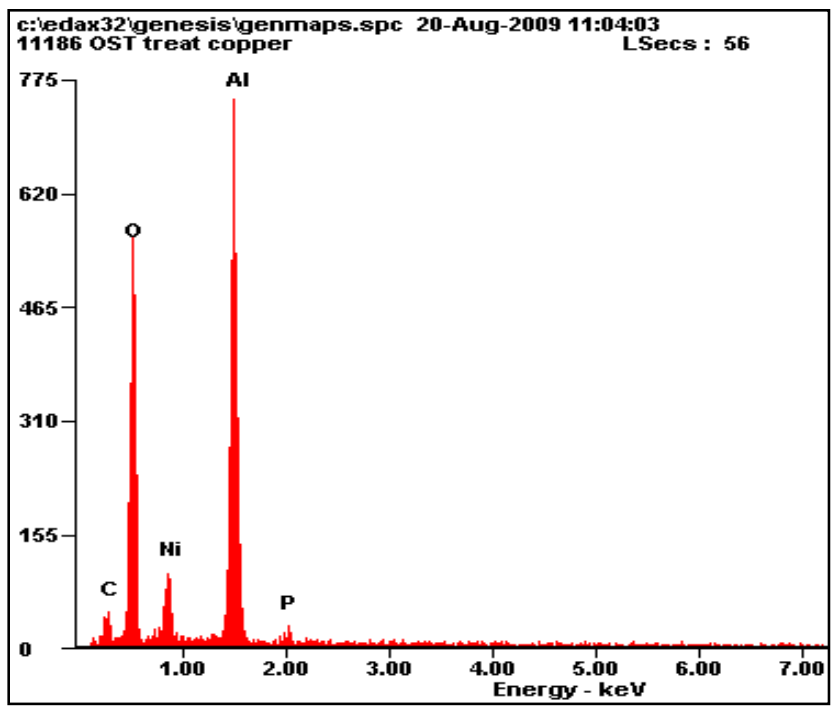

\begin{tabular}{|c|c|c|}
\hline Element & Wt \% & At\% \\
\hline CK & 12.45 & 21.58 \\
\hline OK & 30.60 & 39.81 \\
\hline NiL & 12.41 & 04.40 \\
\hline AlK & 43.07 & 33.22 \\
\hline PK & 01.47 & 00.99 \\
\hline Matrix & Correction & ZAF \\
\hline
\end{tabular}

(b)

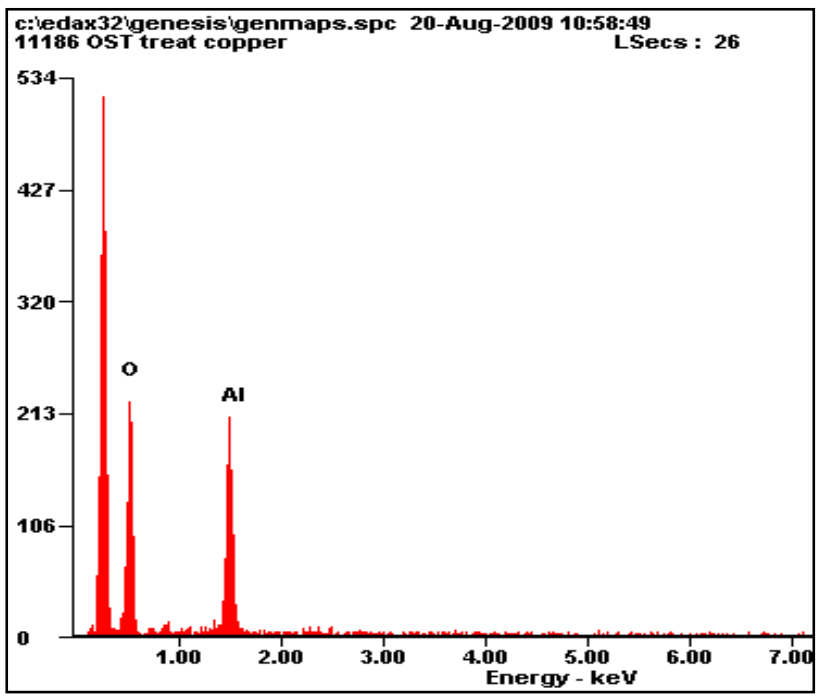

\begin{tabular}{||l|l|l|}
\hline Element & Wt\% & At\% \\
\hline OK & 46.74 & 59.68 \\
\hline AlK & 53.26 & 40.32 \\
\hline Matrix & Correction & ZAF \\
\hline
\end{tabular}

(c)

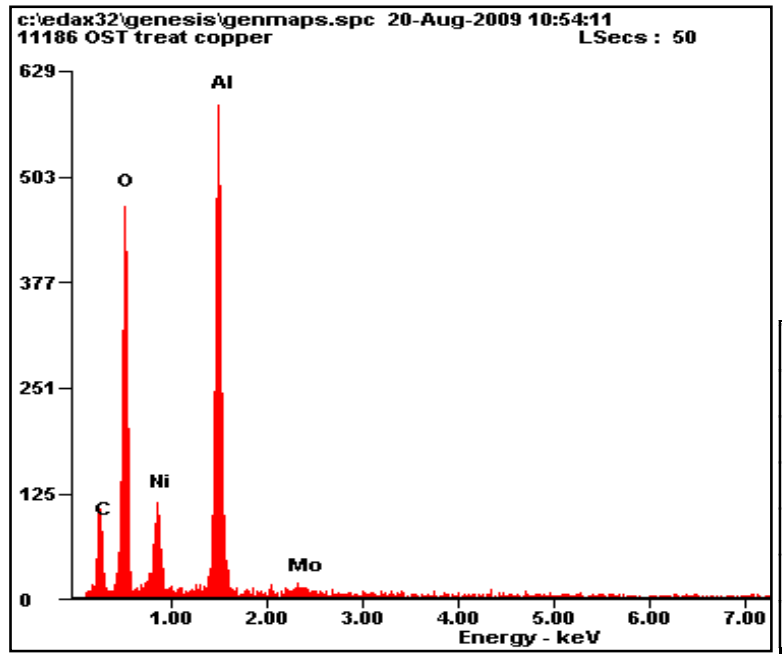

\begin{tabular}{||l|l|l|}
\hline Element & Wt\% & At\% \\
\hline CK & 22.86 & 37.05 \\
\hline OK & 27.72 & 33.72 \\
\hline NiL & 13.19 & 04.37 \\
\hline AlK & 33.76 & 24.36 \\
\hline MoL & 02.47 & 00.50 \\
\hline Matrix & Correction & ZAF \\
\hline
\end{tabular}

(d) 
Several factors could account for the non-proportionality in the amount of Ni plated in the $2 \mathrm{~min}$ samples relative to the 10 min samples: the absence of $\mathrm{Ni}$ and $\mathrm{Mo}$ on the sampled area for the Ni-Mo-P 2 min sample and the lack of phosphorus on the three samples of Figure 2. Such factors could be that our plating method may not have uniformly coated the support particles, thus affecting the wt $\%$ and presence of metal, and the plating time can affect the amount of phosphorus that was co-deposited, since the phosphorus emanates from the decomposition of the reducing agent. At short plating times, the amount of the reducing agent that would have decomposed is expected to be low, thus leading to very low co-deposited P. This is not likely to be the case for long deposition time, as observed in the $10 \mathrm{~min}$ samples. EDAX plots (and compositional charts) are the biggest factor affecting analysis, because they only present a representative section of a sample, so the composition and area percentages given are not completely definitive of the entire catalyst sample.

\subsection{Design of Experiment}

The significance of five factors (electroless solution, plating time, annealing, gas generation temperature and borohydride concentration) on hydrogen generation was examined. Figure 3 represents factor comparisons at set conditions.

Figure 3. Hydrogen evolution rate at $50{ }^{\circ} \mathrm{C}$ and (a) $1.0 \mathrm{wt} \% \mathrm{NaBH}_{4}$; (b) $1.0 \mathrm{wt} \% \mathrm{NaBH}_{4}$; (c) 2 min plating time; (d) 10 min plating time.

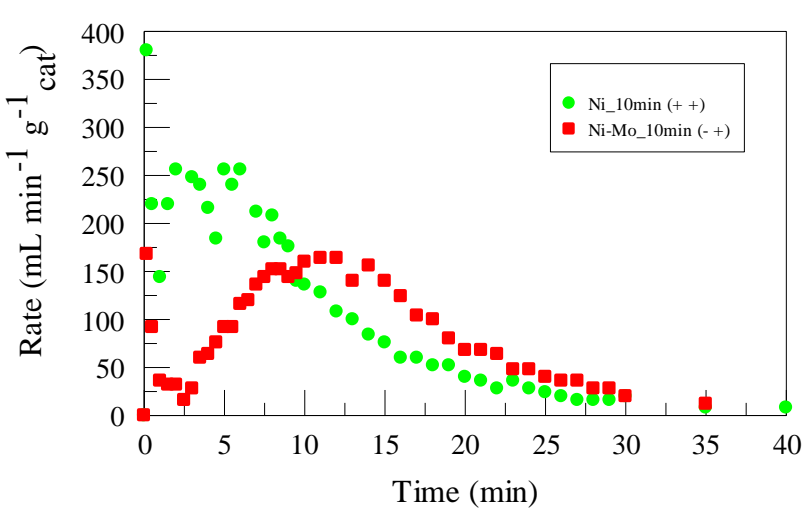

(a)

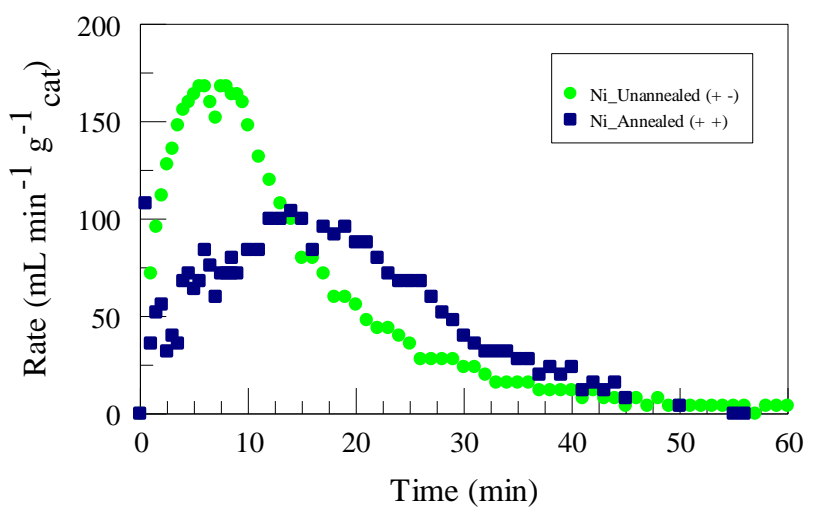

(c)

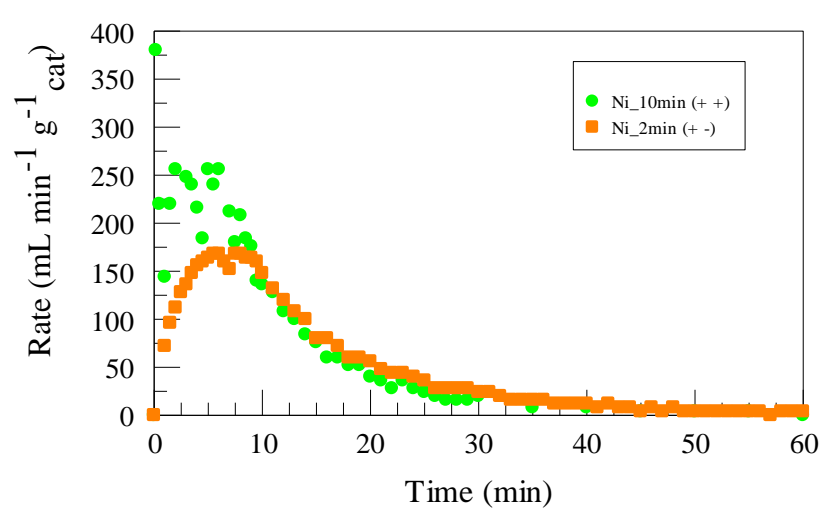

(b)

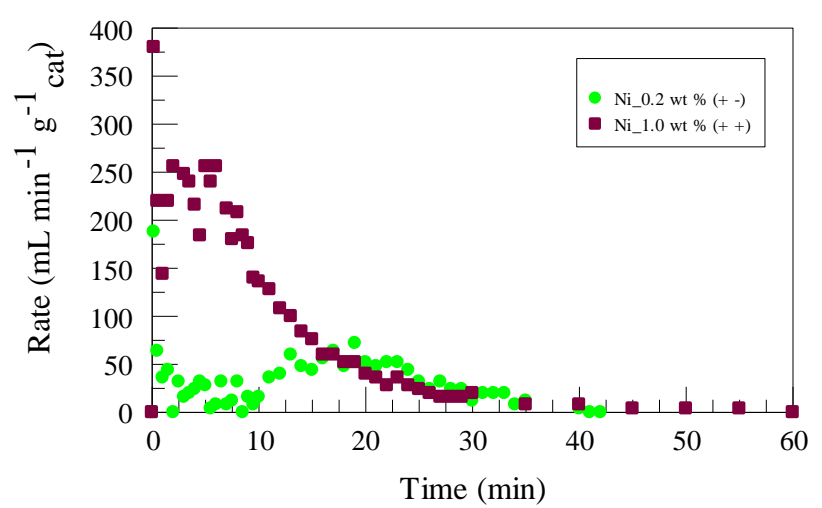

(d) 
The general trend of all the $\mathrm{H}_{2}$ evolution plots shows an initial rise to a peak rate of product generation, then a gentle decline. Along with $\mathrm{H}_{2}$, sodium borate $\left(\mathrm{NaBO}_{2}\right)$ was also being formed. This soluble by-product, once in solution, blankets the catalyst particles on the bottom of the reactor vessel. Since the particles were not stirred (diffusion-limited), coverage of the particles by $\mathrm{NaBO}_{2}$ prevents the rest of the $\mathrm{NaBH}_{4}$ solution from reacting with catalyst and, thus, decreasing the rate of $\mathrm{H}_{2}$ generation.

Figure $3 \mathrm{a}-\mathrm{d}$ represents a comparison between $\mathrm{Ni}$ and $\mathrm{Ni}-\mathrm{Mo}$ at 2 and $10 \mathrm{~min}$ plating times, annealed and unannealed, and borohydride wt $\%$, respectively. The volume of hydrogen generated was calculated by integrating the graphs above over $30 \mathrm{~min}$. With respect to the volume of hydrogen generated in the graphs above, the catalyst configuration and gas generation environment that generated the most hydrogen was the unannealed Ni-P catalyst plated for $10 \mathrm{~min}$ in $1.0 \mathrm{wt} \%$ borohydride (alkaline) solution.

A factorial analysis was performed to calculate the significance of the factors in Table 3 had on the volume of hydrogen generated. Figure 4 is a radar plot for the results of the individual effects of the factorial analysis. The thick black grid-line represents the zero point of the plot, and the effect values for each factor are in parenthesis. The error associated with each factor equals 8.461 and a standard deviation of 23.9 .

Figure 4. Design of experiment (DOE) factor significance.

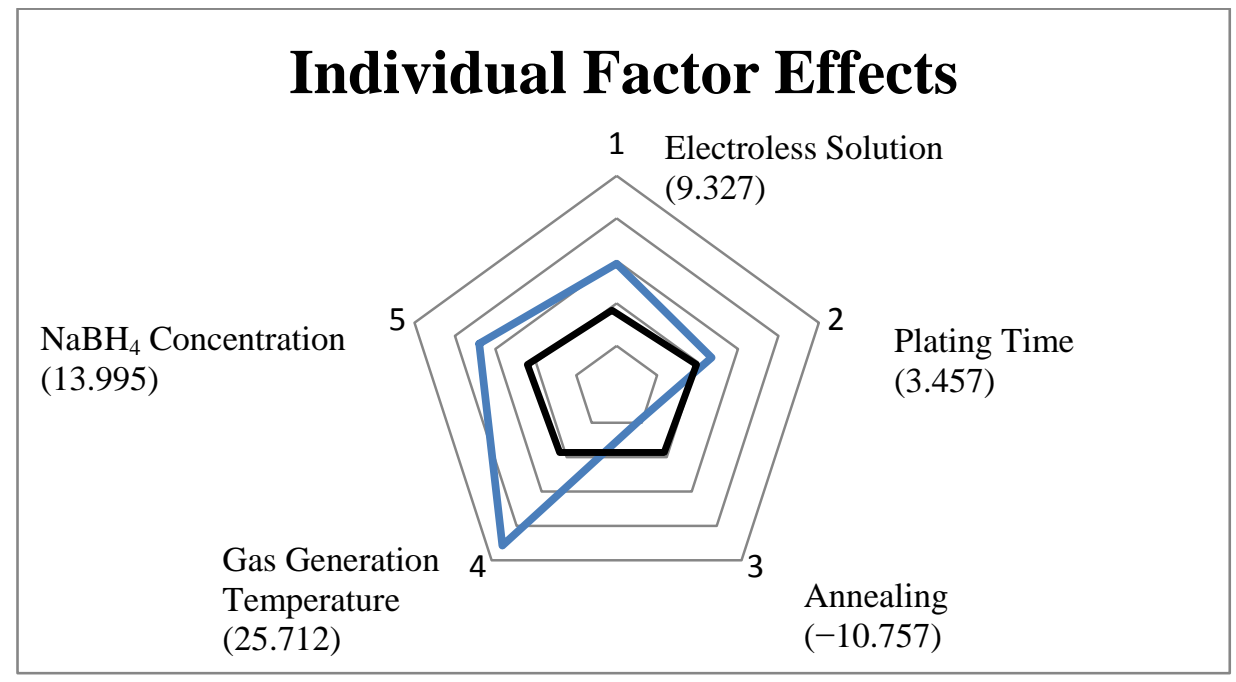

The factorial analysis supports the previous conclusion that the catalyst that generated the most hydrogen is the unannealed Ni-P catalyst plated for $10 \mathrm{~min}$. This configuration was used to determine kinetic parameters in the next section. The reaction that generated the most hydrogen used $1.0 \mathrm{wt} \%$ borohydride alkaline solution at $50{ }^{\circ} \mathrm{C}$.

\subsection{Temperature and Concentration Effects}

Using the same gas generation set-up as the DOE, the effects of borohydride temperature and concentration were tested. Figure 5a plots the average rate in $\mathrm{mL}$ per min per gram of catalyst for the first $5 \mathrm{~min}$ at each temperature for each concentration. 
Figure 5. (a) Rate vs. temperature for the first $5 \mathrm{~min}$; (b) 0.2 wt $\% \mathrm{NaBH}_{4}$ standard error; (c) 0.4 wt $\% \mathrm{NaBH}_{4}$ standard error; (d) $0.6 \mathrm{wt} \% \mathrm{NaBH}_{4}$ standard error.

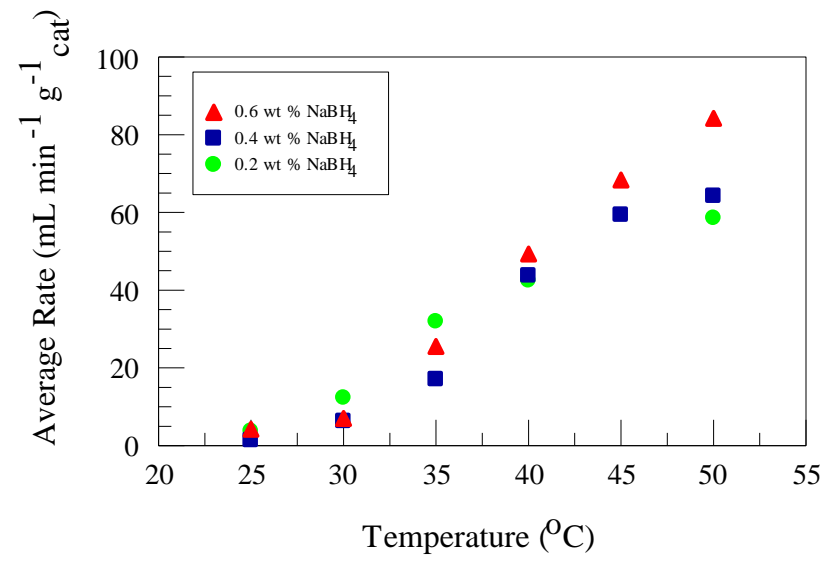

(a)

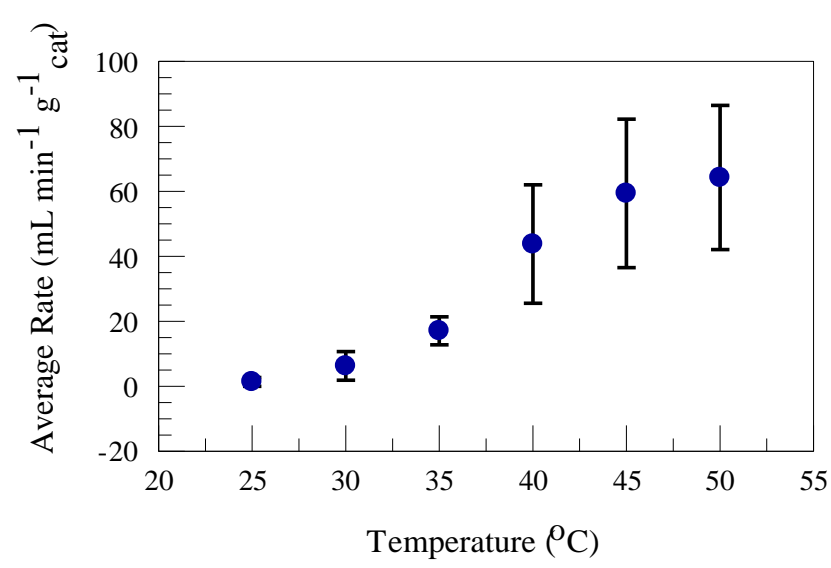

(c)

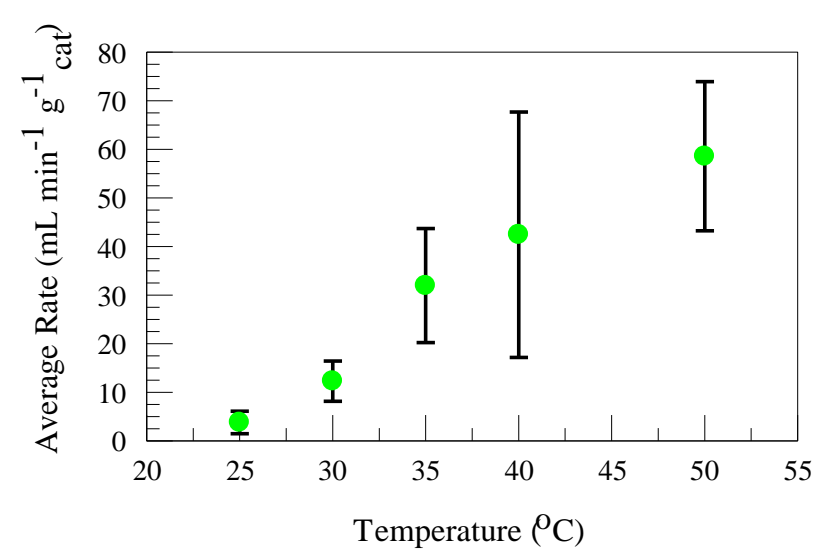

(b)

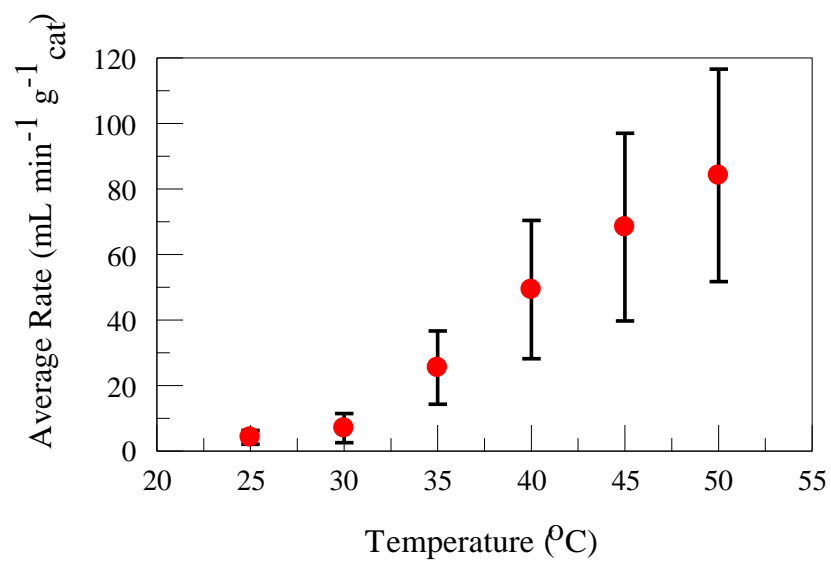

(d)

Reaction kinetics has proven that as the reaction temperature increases, the product generation rate increases, and this plot proves it. At most of the temperatures, the effect of concentration is not well pronounced, which suggests that for the concentration range studied, concentration does not appear to have a significant effect on the $\mathrm{H}_{2}$ generation rate. This suggests a zero order rate with $\mathrm{NaBH}_{4}$ concentration.

\subsection{Kinetic Parameters}

Data collected from the temperature and concentration experiments were analyzed to determine the order of the reaction, $n$, activation energy, $\mathrm{E}_{\mathrm{a}}$, and Arrhenius exponential factor, $\mathrm{k}_{\mathrm{o}}$. The rate equation did not depend on the catalyst composition, since it was kept essentially the same. The average value of the reaction order, $n$, which was estimated from the slope of the natural log of the reaction rate, $r_{\mathrm{H}_{2}}$, versus the natural $\log$ of the $\mathrm{NaBH}_{4}$ concentration obtained at each temperature was slightly greater than zero, but considering the errors inherent in measuring system, we assumed that the kinetics of the hydrolysis is a zero order reaction, in agreement with published literature work [25,26]. Thus, the reaction rate equation, with a modified rate constant, $\mathrm{k}^{\prime}$, and a modified Arrhenius exponential factor, $\mathrm{k}_{\mathrm{o}}{ }^{\prime}$, is: 


$$
-r_{\mathrm{H}_{2}}=\mathrm{k}^{\prime}=\mathrm{k}_{\mathrm{o}}{ }^{\prime} \exp \left(-\frac{\mathrm{E}_{\mathrm{a}}}{\mathrm{RT}}\right)
$$

where:

$$
\mathrm{k}_{\mathrm{o}}{ }^{\prime}=\frac{\mathrm{k}_{\mathrm{o}} \mathrm{P}}{\mathrm{RT}}
$$

where $\mathrm{P}$ is the atmospheric pressure in atm and $\mathrm{T}$ is the room temperature in $\mathrm{K}$. Taking the natural $\log$ of both sides of Equation (2) and preparing a plot of $\ln ($ rate) versus inverse temperature reveals a mostly linear behavior as shown in Figure 6.

Figure 6. Arrhenius plot for all concentrations of $\mathrm{NaBH}_{4}$ solution.

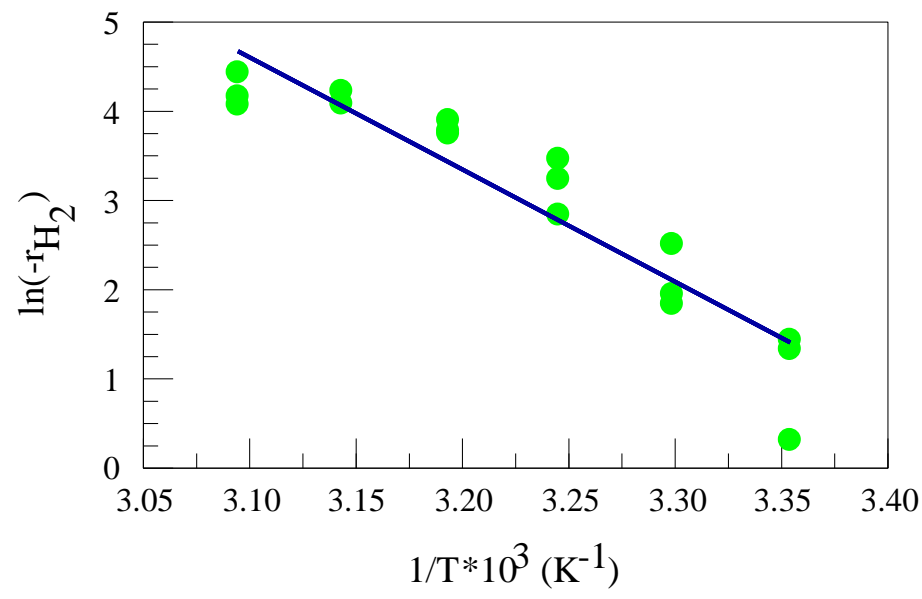

The slope of the best fit line to this data represents the activation energy over the gas constant, $\mathrm{E}_{\mathrm{a}} / \mathrm{R}$, while the $y$-intercept represents the natural $\log$ of the modified Arrhenius exponential factor, $\ln \left(\mathrm{k}_{\mathrm{o}}{ }^{\prime}\right)$.

The activation energy was calculated to equal $104.6 \mathrm{~kJ} / \mathrm{mol}$, the modified Arrhenius exponential factor, $\mathrm{k}_{\mathrm{o}}{ }^{\prime}$, was calculated to equal $8.65 \times 10^{18} \mathrm{~mL} \mathrm{~min}^{-1} \mathrm{~g}^{-1}$ cat, and the actual Arrhenius exponential factor, $\mathrm{k}_{\mathrm{o}}$, was calculated to equal $3.49 \times 10^{15} \mathrm{~mol} \mathrm{~min}^{-1} \mathrm{~g}^{-1}$ cat. The activation energy obtained in this work is about twice the value obtained for Raney nickel $(50.7 \mathrm{~kJ} / \mathrm{mol})$ in [13] and $\mathrm{Ni}-\mathrm{Ru}$ nanocomposite $(52.73 \mathrm{~kJ} / \mathrm{mol})$ in [25].

\section{Experimental Section}

\subsection{Preparing $\mathrm{Ni}-\mathrm{P} / \mathrm{Pd}-\mathrm{Al}_{2} \mathrm{O}_{3}$ and $\mathrm{Ni}-\mathrm{Mo}-\mathrm{P} / \mathrm{Pd}-\mathrm{Al}_{2} \mathrm{O}_{3}$}

Supported metal catalysts were prepared using electroless deposition on topolymer-stabilized palladium nanoparticle-catalyzed and activated aluminum oxide $\left(\mathrm{Al}_{2} \mathrm{O}_{3}\right)$. In the present work, palladium nanoparticle was first deposited on the surface of $\mathrm{Al}_{2} \mathrm{O}_{3}$ through thermal activation in an oven or furnace of palladium-ink coated $\mathrm{Al}_{2} \mathrm{O}_{3}$ particles. The purpose of palladium nanoparticle was to initiate the electroless deposition (oxidation-reduction) reaction for plating the metal or composite-metal catalyst of choice for the hydrolysis reaction. $\mathrm{Al}_{2} \mathrm{O}_{3}$ is a very porous substance and, thus, provides a large surface area $\left(\sim 1.69 \mathrm{~m}^{2} / \mathrm{g}\right)$ for depositing the $\mathrm{Pd}$. The experimental steps involve the following: $0.2 \mathrm{~g}$ of analytical reagent grade palladium acetate $\left[\mathrm{Pd}\left(\mathrm{CH}_{3} \mathrm{CO}_{2}\right)_{2}\right]_{3}(47.05 \% \mathrm{Pd})$ from 
Aldrich-Sigma company was dissolved in $2.0 \mathrm{~mL} \mathrm{NH} 4 \mathrm{OH}$. The dissolved $\mathrm{Pd}$ acetate $/ \mathrm{NH}_{4} \mathrm{OH}$ mixture was added with stirring to a $44 \mathrm{~g}$ methanol-Poly (Vinyl) Butyral (PVB) (Solutia Inc.'s Butvar B-98) mixture formed by dissolving $22 \mathrm{~g}$ PVB in $140 \mathrm{~mL}$ methanol. The resulting mixture is referred to as the $\mathrm{Pd}$ ink. In order to make $\mathrm{Al}_{2} \mathrm{O}_{3}$ active for electroless deposition, a known amount of $\mathrm{Pd}$ ink $(\sim 21 \mathrm{~g})$ was mixed with a known amount of $\mathrm{Al}_{2} \mathrm{O}_{3}(\sim 30 \mathrm{~g}$, Anhydrous, Fisher Scientific, Pittsburgh, PA, USA). The Pd ink mixture was then thoroughly mixed with the $\mathrm{Al}_{2} \mathrm{O}_{3}$ until all the particles were coated. After drying at about $50{ }^{\circ} \mathrm{C}$, the mixture was placed in a $250{ }^{\circ} \mathrm{C}$ furnace for $24 \mathrm{~h}$. The annealing process thermally degrades the excess polymer and leaves carbon-coated Pd attached on the surface of the support. The high temperature heating and annealing also reduces the $\mathrm{Pd}$ from $\mathrm{Pd}^{2+}$ to $\mathrm{Pd}^{0}$. The previously inert $\mathrm{Al}_{2} \mathrm{O}_{3}$ substrate is now active for electroless deposition. Ni-P and Ni-Mo-P are prepared with the components in Tables 1 and 2:

Table 1. Composition of electroless Ni-P solution.

\begin{tabular}{cc}
\hline Material & Quantity (g/L) \\
\hline Sodium Hypophosphite & 10 \\
Gluconic Acid & 10 \\
NaK Tartrate & 10 \\
Nickel Sulfate & 7 \\
Boric Acid & 10 \\
EDTA & 5 \\
Glycine & 10 \\
\hline
\end{tabular}

Table 2. Composition of electroless Ni-Mo-P solution.

\begin{tabular}{cc}
\hline Material & Quantity $(\mathrm{g} / \mathbf{L})$ \\
\hline Sodium Hypophosphite & 10 \\
Gluconic Acid & 15 \\
NaK Tartrate & 10 \\
Nickel Sulfate & 7 \\
Sodium Molybdenum Oxide & 3.94 \\
\hline
\end{tabular}

Nickel (II) sulfate hexahydrate (Sigma-Aldrich, St. Louis. MO, USA) and sodium molybdenum oxide $\left(\mathrm{Na}_{2} \mathrm{MoO}_{4} \cdot 2 \mathrm{H}_{2} \mathrm{O}\right.$, Alfa Aesar, Ward Hill, MA, USA) were used as the metal source, sodium hypophosphite monohydrate (Alfa Aesar, Ward Hill, MA, USA) was used as the reducing agent, which also forms a source of phosphorous in the deposit. Boric acid (Fisher Scientific, Pittsburgh, PA, USA) was also used as a buffering agent. Ethylene diamine tetraacetic acid (EDTA) (Aldrich Chemicals, St. Louis, MO, USA), gluconic acid (K-salt, MP Biomedicals, Santa Ana, CA, USA), sodium potassium tartrate tetrahydrate (VWR, Radnor, PA, USA) and glycine (J.T. Baker, Center Valley, PA, USA) were used as chelating agents. A $500 \mathrm{~mL}$ stock of electroless Ni-P or Ni-Mo-P solution was prepared in a volumetric flask and used in depositing the Ni metals or Ni-Mo alloy onto the $\mathrm{Pd}$ catalyzed $\mathrm{Al}_{2} \mathrm{O}_{3}$ substrate. The solution was heated and maintained at $75 \pm 2{ }^{\circ} \mathrm{C}$ in a constant temperature bath. Ammonium hydroxide was used to adjust and maintain a $\mathrm{pH}$ of $10 \pm 0.5$. The solution's container oscillated at $90 \mathrm{rpm}$ to agitate the contents. Once reaction conditions were met, $1 \mathrm{~g}$ of Pd-catalyzed substrate was added and allowed to react for a specified amount of time. The Pd on 
the substrate initiated the reaction and once the surface was coated in one layer of metal, the metal plating continued through a process of autocatalytic plating, whereby the plating metal acts as the catalyst for a further plating reaction. After plating, the coated particles were filtered, rinsed several times with deionized (DI) water, until the water was neutral, then the plated particles were dried in a $50{ }^{\circ} \mathrm{C}$ oven. About half of the dried catalyst was annealed under nitrogen at $250{ }^{\circ} \mathrm{C}$ for $45 \mathrm{~min}$.

\subsection{Testing Catalytic Activity}

Catalytic activity was tested through an estimation of the amount of hydrogen generated during the hydrolysis of $\mathrm{NaBH}_{4}$ for a known amount of time. Aqueous alkaline borohydride solutions were prepared with a constant alkalinity molar ratio (moles of $\mathrm{NaBH}_{4}$ to moles of $\mathrm{NaOH}$ ) of 0.08 . The gas generation set-up included a $40 \mathrm{~mL}$ glass vial reactor connected with a reverse flow prevention connector to a hydrogen selective gas flow meter (RESTEK 6000 Solid State Flowmeter). A constant temperature bath was used to adjust and maintain the temperature inside the reactor. For each gas evolution experiment, $20 \mathrm{~mL}$ of alkaline borohydride solution was placed in the reactor. After the reactor was equilibrated in the constant bath temperature, approximately 25 milligrams of the electroless catalyst sample was placed inside the reactor, the reactor was sealed and the gas flowed out of the reactor to the hydrogen selective gas flow meter. No stirring was implemented inside the reactor. The flow rate of evolved hydrogen was measured and recorded over time. The evolved gas rate over time was integrated to obtain the total volume of hydrogen generated.

A design of experiment was used to test five factors to estimate the significance of their effects in the hydrogen evolution reaction. Table 3 provides the factor levels used in the design of experiment. The results of the $2^{5}$ (32) experiments conducted were analyzed over time to calculate the volume of hydrogen generated during the first $30 \mathrm{~min}$ for each set of conditions.

Table 3. Experimental factors.

\begin{tabular}{cccccc}
\hline Factor & $\begin{array}{c}\text { Electroless } \\
\text { Solution }\end{array}$ & $\begin{array}{c}\text { Plating Time } \\
(\mathbf{m i n})\end{array}$ & $\begin{array}{c}\text { Annealing } \\
\left(\text { under } \mathbf{N}_{\mathbf{2}}\right)\end{array}$ & $\begin{array}{c}\text { Gas Generation } \\
\text { Temperature }\left({ }^{\circ} \mathbf{C}\right)\end{array}$ & $\begin{array}{c}\mathbf{N a B H}_{\mathbf{4}} \\
\text { Concentration }\end{array}$ \\
\hline Factor number & 1 & 2 & 3 & 4 & 5 \\
+ & $\mathrm{Ni}$ & 10 & $\mathrm{Yes}$ & 50 & $1.0 \mathrm{wt} \%$ \\
- & $\mathrm{Ni}-\mathrm{Mo}$ & 2 & $\mathrm{No}$ & 25 & $0.2 \mathrm{wt} \%$ \\
\hline
\end{tabular}

Once the catalyst configuration that evolved the most hydrogen was determined, hydrogen evolution experiments were conducted at different hydrolysis temperatures ranging from 25 to $50{ }^{\circ} \mathrm{C}$ and at three different levels of $\mathrm{NaBH}_{4}$ concentrations $(0.05,0.10$ and $0.15 \mathrm{M})$ in order to calculate kinetic parameters. Rakap et al. [27] have demonstrated that a Co-Ni-P catalyst prepared through a similar method as our present work and used in sodium borohydride hydrolysis has multiple reusability. It is our premise that the present catalyst would show the same capability and maintain its activity for multiple usage. Scanning Electron Micrographs (SEM) and Energy Dispersive X-Ray Microanalysis (EDAX) were used to analyze the samples. The images included in this report were obtained from the usage of a Zeiss 1540 XB Cross Beam Scanning Electron Microscope (SEM) equipped with an EDAX detecting unit for atomic composition. Only freshly prepared or deposited samples were characterized using SEM and Energy Dispersive X-ray Spectrometer (EDAX). 


\section{Conclusions}

An electrolessly prepared Ni catalyst was used to generate hydrogen through hydrolysis of alkaline sodium borohydride solutions. EDAX plots showed that metals did plate onto the surface and that a longer plating time deposited more metal. SEM images showed that highly porous $\mathrm{Al}_{2} \mathrm{O}_{3}$ support plated with electroless composite metals remained porous after plating.

Statistical analysis showed that the most significant factor in $\mathrm{H}_{2}$ generation is the reaction temperature; higher temperatures generate more $\mathrm{H}_{2}$. Kinetics also proves this to be true. Contrary to previous notions, annealing had a negative effect on the $\mathrm{H}_{2}$ generation, possibly due to mishandling samples and oxides forming on the surface of the catalyst. The final catalyst composition that was determined was electroless $\mathrm{Ni}$, as-plated for $10 \mathrm{~min}$.

Kinetic parameters were estimated for this catalyst. The reaction order was determined to be zero order, the activation energy estimated to be $104.6 \mathrm{~kJ} / \mathrm{mol}$ and the actual Arrhenius exponential factor equaled $3.49 \times 10^{15} \mathrm{~mol} \mathrm{~min}^{-1} \mathrm{~g}^{-1}$ cat. The error associated with the measurement tool affected some of the results significantly. Because the catalyst was not stirred during hydrogen generation, the evolved hydrogen can be considered the minimum hydrogen rate for the catalyst samples.

The overall goal of this research was to develop a process of generating $\mathrm{H}_{2}$ for small fuel cell applications. Future works include characterizing fresh and used electroless catalyst samples with XRD and TEM, as well as understanding the mechanism of the reaction. The results of the present investigation are encouraging in meeting such goals, thus suggesting that our approach for catalyst synthesis has high potential applicability when optimized.

\section{Acknowledgments}

The authors acknowledge the support of the Partnership for Research and Education in Materials initiative of the National Science Foundation under NSF Award 0351770, NSF Grant No. DMR-0351770.

\section{Conflict of Interest}

The authors declare no conflict of interest.

\section{References and Notes}

1. Chamoun, R.; Demirci, U.B.; Zaatar, Y.; Khoury, A.; Miele, P. Co- $\alpha \mathrm{Al}_{2} \mathrm{O}_{3}-\mathrm{Cu}$ as shaped catalyst in $\mathrm{NaBH}_{4}$ hydrolysis. Int. J. Hydrog. Energy 2010, 35, 6583-6591.

2. In accordance with the USDOE definitions, the term "gravimetric hydrogen storage capacity" (GHSC) is used for storage system taken as a whole (i.e., including all components such as the hydride, tank, valves and so on). Hence, we use the term "hydrogen density" (HD) as the theoretical storage capacity of the hydride (wt \%).

3. Chandra, M.; Xu, Q. A high-performance hydrogen generation system: Transition metal-catalyzed dissociation and hydrolysis of ammonia-borane. J. Power Sources 2006, 156, 190-194.

4. Jiang, H.L.; Xu, Q. Catalytic hydrolysis of ammonia borane for chemical hydrogen storage. Catal. Today 2011, 170, 56-63. 
5. Yadav, M.; Xu, Q. Liquid-phase chemical hydrogen storage materials. Energy Environ. Sci. 2012, 5, 9698-9725.

6. Lu, Z.-H. Recent Progress in Boron- and Nitrogen-Based Chemical Hydrogen Storage. Funct. Mater. Lett. 2012, 5, 1230001:1-1230001:9

7. Kim, D.R.; Cho, K.W.; Choi, Y.I.; Park, C.J. Fabrication of porous Co-Ni-P catalysts by electrodeposition and their catalytic characteristics for the generation of hydrogen for an alkaline $\mathrm{NaBH}_{4}$ solution. Int. J. Hydrog. Energy 2009, 34, 2622-2623.

8. Eom, K.S.; Kwon, H.S. Effects of deposition time on the $\mathrm{H}_{2}$ generation kinetics of electroless-deposited cobalt-phosphorous catalyst from $\mathrm{NaBH}_{4}$ hydrolysis, and its cyclic durability. Int. J. Hydrog. Energy 2010, 35, 5220-5221.

9. Peng, B.; Chen, D. Ammonia borane as an efficient and lightweight hydrogen medium. Energy Environ. Sci. 2008, 1, 479-483.

10. Umegaki, T.; Yan, J.M.; Zhang, X.B.; Shioyama, H.; Kuriyama, N.; Xu, Q. Boron- and nitrogen-based chemical hydrogen storage materials. Int. J. Hydrog. Energy 2008, 34, 2303-2311.

11. Demirci, U.B.; Miele, P. Sodium borohydride versus ammonia borane, in hydrogen storage and direct fuel cell applications. Energy Environ. Sci. 2009, 2, 627-637.

12. Sahin, Ö.; Dolas, H.; Kaya, M.; Izgi, M.S.; Demir, H. Hydrogen production from sodium borohydride for fuel cells in presence of electrical field. Int. J. Energy Res. 2010, 34, 557-558.

13. Liu, B.H.; Li, Z.P.; Morigasaki, N.; Suda, S. Kinetic characteristics of sodium borohydride formation when sodium meta-borate reacts with magnesium and hydrogen. Int. J. Hydrog. Energy 2008, 33, 1323-1328.

14. Kim, T. Hydrogen generation from sodium borohydride using microreactor for micro fuel cells. Int. J. Hydrog. Energy 2011, 36, 1404-1405.

15. Zhang, J.S.; Delgass, W.N.; Fisher, T.S.; Gore, J.P. Kinetics of Ru catalyzed sodium borohydride hydrolysis. J. Power Sources 2007, 164, 772-781.

16. Kojima, Y.; Suzuki, K.; Fukumoto, K.; Kawai, Y.; Kimbara, M.; Nakanishi, H. Development of $10 \mathrm{~kW}$-scale hydrogen generator using chemical hydride. J. Power Sources 2004, 125, 22-26.

17. Patel, N.; Patton, B.; Zanchetta, C.; Fernandes, R.; Guella, G.; Kale, A.; Miotello, A. Pd-C powder and thin film catalysts for hydrogen production by hydrolysis of sodium borohydride. Int. J. Hydrog. Energy 2008, 33, 287-292.

18. Amendola, S.C.; Onnerud, P.; Kelly, M.T.; Petillo, P.J.; Sharp-Goldman, S.L.; Binder, M. An ultrasafe hydrogen generator: Aqueous, alkaline borohydride solutions and Ru catalyst. J. Power Sources 2000, 85, 186-189.

19. Amendola, S.C.; Sharp-Goldman, S.L.; Janjua, M.S.; Spencer, N.C.; Kelly, M.T.; Petillo, P.J. Safe, portable, hydrogen gas generator using aqueous borohydride solution and Ru catalyst. Int. J. Hydrog. Energy 2000, 25, 969-975.

20. Andrieux, J.; Demirci, U.B.; Miele, P. Langmuir-Hinshelwood kinetic model to capture the cobalt nanoparticles-catalyzed hydrolysis of sodium borohydride over a wide temperature range. Catal. Today 2011, 170, 13-19. 
21. Rakap, M.; Kalu, E.E.; Özkar, S. Hydrogen generation from the hydrolysis of ammonia borane using cobalt-nickel-phosphorous (Co-Ni-P) catalyst supported on Pd-activated $\mathrm{TiO}_{2}$ by electroless deposition. Int. J. Hydrog. Energy 2011, 36, 254-261.

22. Wu, C.; Bai, Y.; Liu, D.X.; Wu, F.; Pang, M.L.; Yi, B.L. Ni-Co-B catalyst-promoted hydrogen generation by hydrolysis $\mathrm{NaBH}_{4}$ solution for in situ hydrogen supply of portable fuel cells. Catal. Today 2011, 170, 33-39.

23. Oh, T.H.; Kwon, S. Effect of manufacturing conditions on properties of electroless deposited $\mathrm{Co}-\mathrm{P} / \mathrm{Ni}$ foam catalyst for hydrolysis of sodium borohydride solution. Int. J. Hydrog. Energy $\mathbf{2 0 1 2}$, $37,15925-15937$.

24. Oh, T.H.; Kwon, S. Effect of bath composition on properties of electroless Co-P/Ni foam catalyst for hydrolysis of sodium borohydride solution. Int. J. Hydrog. Energy 2012, 37, 17027-17039.

25. Liu, C.H.; Chen, B.H.; Hsueh, C.L.; Ku, J.R.; Jeng, M.S.; Tsau, F. Hydrogen generation from hydrolysis of sodium borohydride using Ni-Ru nanocomposite as catalyst. Int. J. Hydrog. Energy 2009, 34, 2153-2163.

26. Ingersoll, J.C.; Mani, N.; Thenmozhiyal, J.C.; Muthaiah, A. Catalytic hydrolysis of sodium borohydride by a novel nickel-cobalt-boride catalyst. J. Power Sources 2007, 173, 450-457.

27. Rakap, M; Kalu, E.E.; Özkar, S. Cobalt-nickel-phosphorus supported on Pd-activated $\mathrm{TiO}_{2}$ $\left(\mathrm{Co}-\mathrm{Ni}-\mathrm{P} / \mathrm{Pd}-\mathrm{TiO}_{2}\right)$ as cost-effective and reusable catalyst for hydrogen generation from hydrolysis of alkaline sodium borohydride solution. J. Alloys Compd. 2011, 509, 7016-7021.

(C) 2013 by the authors; licensee MDPI, Basel, Switzerland. This article is an open access article distributed under the terms and conditions of the Creative Commons Attribution license (http://creativecommons.org/licenses/by/3.0/). 